\title{
Morphology and photoluminescence study of titania nanoparticles
}

\author{
Mine Memesa • Sebastian Lenz • Sebastian G. J. Emmerling • Sebastian Nett • \\ Jan Perlich • Peter Müller-Buschbaum • Jochen S. Gutmann
}

Received: 21 December 2010 /Revised: 6 March 2011 / Accepted: 8 March 2011 /Published online: 2 April 2011

(C) The Author(s) 2011. This article is published with open access at Springerlink.com

\begin{abstract}
Titania nanoparticles are prepared by sol-gel chemistry with a poly(ethylene oxide) methyl ether methacrylate-block-poly(dimethylsiloxane)-block-poly (ethylene oxide) methyl ether methacrylate triblock copolymer acting as the templating agent. The sol-gel components - hydrochloric acid, titanium tetraisopropoxide, and triblock copolymer - are varied to investigate their effect on the resulting titania morphology. An increased titania precursor or polymer content yields smaller primary titania
\end{abstract}

M. Memesa $(\bowtie) \cdot$ S. Lenz $\cdot$ S. G. J. Emmerling $\cdot$ S. Nett $\cdot$

J. S. Gutmann

Max Planck Institute for Polymer Research,

Ackermannweg 10,

55128 Mainz, Germany

e-mail: minememesa@gmail.com

J. Perlich • P. Müller-Buschbaum

Lehrstuhl für Funktionelle Materialien,

Technische Universität München,

Physik-Department E13, James-Franck-Str. 1,

85747 Garching, Germany

Present Address:

J. S. Gutmann

Deutsches Textilforschungszentrum Nord-West e.V., Institut an

der Universität Duisburg-Essen,

Adlerstraße 1,

47798 Krefeld, Germany

Present Address:

M. Memesa

Materials Science and Technology of Polymers, MESA+ Institute

for Nanotechnology, University of Twente,

P.O. Box 217, 7500 AE Enschede, the Netherlands

Present Address:

J. Perlich

HASYLAB at DESY,

Notkestr. 85,

22607 Hamburg, Germany structures. Microbeam grazing incidence small-angle X-ray scattering measurements, which are analyzed with a unified fit model, reveal information about the titania structure sizes. These small structures could not be observed via the used microscopy techniques. The interplay among the sol-gel components via our triblock copolymer results in different sized titania nanoparticles with higher packing densities. Smaller sized titania particles, $(\sim 13-20 \mathrm{~nm}$ in diameter) in the range of exciton diffusion length, are formed by $2 \%$ by weight polymer and show good crystallinity with less surface defects and high oxygen vacancies.

Keywords Titania $\cdot \mu$ GISAXS $\cdot$ Sol-gel $\cdot$ PL $\cdot$ DSSC

\section{Introduction}

Nanostructured titania particles are very attractive for several applications such as photocatalysis, coating, gas sensing, and photovoltaics [1,2]. The morphology and crystallinity of the titanium dioxide $\left(\mathrm{TiO}_{2}\right)$ particles greatly influence the efficiencies in these applications [3-5]. The active sites on titania surface are controlled by the morphology of the titania films. Moreover, charge carrier transfer rates are greatly influenced by morphology as it impacts carrier delocalization routes [6-8]. The electronic structure of $\mathrm{TiO}_{2}$ is further controlled by its crystallinity. Among three different crystallographic polymorphs of $\mathrm{TiO}_{2}$ - anatase, rutile, and brookite - anatase can be prepared as thermodynamically metastable nanocrystals with a wide band gap, $3.2 \mathrm{eV}$. This makes anatase the appropriate choice for semiconductor applications [9-12]. The macroscopic homogeneity of the titania films over large areas is a crucial requirement for applications in photovoltaic devices. Hence, the preparation of nanostructured $\mathrm{TiO}_{2}$ thin films 
has gained special significance. Our group reported the preparation of titania nanoparticles with desired morphologies in a reproducible way $[13,14]$. An amphiphilic block copolymer, poly(styrene)-block-poly(ethylene oxide) (PS$b$-PEO), acting as template, was dissolved in tolueneisopropanol mixture, and the titania precursor, titanium (IV) tetraisopropoxide (TTIP), was subsequently incorporated into the micelles. The sol-gel was spin-coated, and after calcination at $450{ }^{\circ} \mathrm{C}$, anatase titania nanoparticles were obtained. A ternary phase diagram was mapped using a good-poor solvent pair by changing the relative weight fractions between 1,4-dioxane, hydrochloric acid $(\mathrm{HCl})$, and TTIP. It serves as a guide for the preparation of nanocomposite films with different morphologies [15]. A triblock copolymer of PEO-PS-PEO was also used as the templating agent in good-poor solvent-induced phase separation via sol-gel chemistry and resulted in macroporous anatase $\mathrm{TiO}_{2}$ thin films [16].

These ordered anatase titania thin films have potential application in dye-sensitized solar cell (DSSC) devices. If the hybrid films are to be used as an alternative blocking layer, an additional insulation property has to be incorporated in between semiconducting anatase titania nanoparticles [17]. When there is no insulation in between titania nanoparticles, the transparent fluorine-doped tin oxide/indium tin oxide substrate is in direct contact with the hole transport medium; charge recombination is favored and intrinsically inefficient solar cells are obtained. In order to incorporate insulating parts in between titania nanoparticles, preparation of titania nanoparticles using an amphiphilic block copolymer as the templating agent by sol-gel chemistry was extended with the help of a poly (dimethylsiloxane) (PDMS)-containing amphiphilic block copolymer [17-19]. PDMS is one of polymeric precursors of the general formula $\left(\mathrm{R}_{x} \mathrm{Si}\left(\mathrm{OR}^{\prime}\right)_{4}{ }_{-x}\right)$ containing $\mathrm{Si}-\mathrm{C}$ bonds. This $\mathrm{Si}-\mathrm{C}$ bond is present from the beginning in the sol-gel process and preserved in glass structures. These silicon oxycarbide gels were heat-treated to intermediate temperatures to obtain silicon oxycarbide glasses [20]. Poly (ethylene oxide) methyl ether methacrylate-block-poly (dimethylsiloxane)-block-poly(ethylene oxide) methyl ether methacrylate [(PEO)MA-PDMS-MA(PEO)] triblock copolymer was used as the templating agent. In previous works, (PEO)MA-PDMS-MA(PEO) triblock copolymer acted as the templating agent in combination with sol-gel chemistry to prepare conductive anatase titania nanoparticles embedded in a polymer-derived ceramic using $1 \%$ by weight of the triblock copolymer, $\mathrm{HCl}$, and titania precursor[17].

In this paper, we investigate the effect of sol-gel components on the prepared titania morphology and their photophysical properties when the conductive anatase titania nanoparticles are prepared in an insulating matrix. The sol-gel components- $\mathrm{HCl}$, triblock copolymer (referred to as "polymer" in the rest of the text for simplicity), and titania precursor (TTIP) - are varied individually as depicted in Scheme 1.

The polymer is first dissolved in a tetrahydrofuranisopropanol mixture in a ratio of 3:1 to achieve complete dissolution of PDMS and (PEO)MA blocks, followed by successive addition of $\mathrm{HCl}$ and TTIP within 2 min. The concentrated $\mathrm{HCl}$ is a poor solvent for the PDMS block. Thus, the interfacial energy between the PDMS block and the solvents increases and leads to the formation of micelles in solution. TTIP, also a poor solvent for PDMS, incorporates into the hydrophilic PEO domains via coordination bonds. TTIP hydrolyzes, catalyzed by $\mathrm{HCl}$, and condenses on PEO domains. These titania structures can form covalent Ti-O bonds with neighboring micelles, resulting in a titania network formation. A complex force balance between polymer chain stretching and polymer solvent interactions determines the morphologies [21-24]. Different morphologies can be obtained by varying the weight fractions between $\mathrm{HCl}$ and TTIP. Furthermore, the block copolymer concentration controls the resulting micellar morphologies in the sol-gel. To understand how the changes in $\mathrm{HCl}$, TTIP, and block copolymer, i.e., sol-gel components, concentration control the morphology of titania structures, we varied the sol-gel components (Scheme 1).

In the presented work, we investigate the morphology with scanning electron and force microscopy techniques. Moreover, microbeam grazing incidence small-angle X-ray scattering ( $\mu$ GISAXS) experiments reveal information from the inside morphology that could not be obtained via microscopy techniques. In addition, photoluminescence (PL) spectroscopy gives information of the photoelectronic properties of particles prepared from a variation of the sol-gel components after preparation and upon heating at $450{ }^{\circ} \mathrm{C}$.

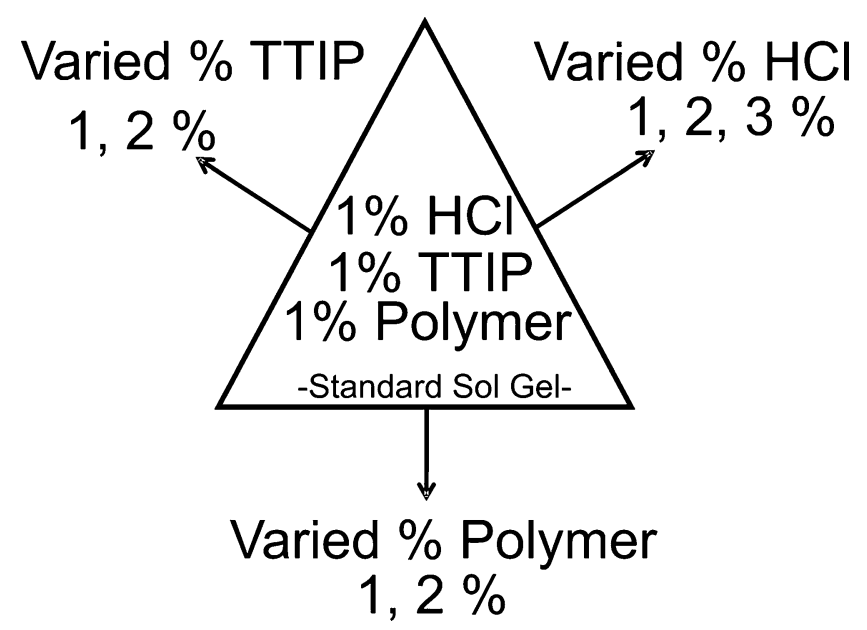

Scheme 1 Variation of the sol-gel components 
The increase in the titania precursor and the polymer amount result in smaller primary titania particles. This represents a promising preparation route for applications that require conductive titania particle sizes on the order of 13-20 nm, namely photovoltaic applications [25].

\section{Experimental section}

\section{Materials}

(PEO)MA-PDMS-MA(PEO) triblock copolymer was synthesized as explained elsewhere [17]. TTIP (Aldrich, $99.9 \%)$, hydrochloric acid $(37 \%, \mathrm{HCl}$, Acros, Geel, Belgium), isopropanol (Acros), and tetrahydrofuran (THF, extra dry from Acros) were used without further purification.

(PEO)MA-PDMS-MA(PEO)/titania nanocomposite film preparation

Sample solutions were prepared by dissolving $40.5 \mathrm{mg}$ of (PEO)MA-PDMS-MA(PEO) block copolymer in 3,004 mg THF and 1,008 mg isopropanol. Forty-five milligrams titania precursor (TTIP) and $47 \mathrm{mg} \mathrm{HCl}$ were added and stirred for $1 \mathrm{~h}$ at ambient temperature. These amounts were for $1 \% \mathrm{HCl}, 1 \%$ TTIP, and $1 \%$ block copolymer by weight over the total components. The amount of $\mathrm{HCl}$ was varied to $2 \%$ and $3 \%$ of the total amount. In a typical experiment, component amounts were $43.8 \mathrm{mg}$ of (PEO)MA-PDMSMA(PEO) block copolymer, 3,007 mg THF, 1,004 mg isopropanol, $43.8 \mathrm{mg}$ TTIP, $84.6 \mathrm{mg} \mathrm{HCl}$ for $2 \% \mathrm{HCl}$ and $42.4 \mathrm{mg}$ of (PEO)MA-PDMS-MA(PEO) block copolymer, 3,006 mg THF, $1,002 \mathrm{mg}$ isopropanol, $45.5 \mathrm{mg}$ TTIP, $140.7 \mathrm{mg} \mathrm{HCl}$ for $3 \% \mathrm{HCl}$. Block copolymer amount was also varied to $2 \%$ by weight: $92.6 \mathrm{mg}$ of (PEO)MA-PDMSMA(PEO) block copolymer, 3,021 mg THF, 1,013 mg isopropanol, $42.2 \mathrm{mg}$ TTIP, $43.8 \mathrm{mg} \mathrm{HCl}$. Titania precursor amount was varied to $2 \%$ by weight: $40.2 \mathrm{mg}$ of (PEO)MAPDMS-MA(PEO) block copolymer, 3,016 mg THF, $1,017 \mathrm{mg}$ isopropanol, $82.6 \mathrm{mg}$ TTIP, $40 \mathrm{mg} \mathrm{HCl}$. At least four specimens from each concentration were prepared.

Nanocomposite films were prepared on $\mathrm{Si}(100)$ substrates by spin coating each sample solution for $60 \mathrm{~s}$ using a Süss MicroTec Delta 80 spin coater under ambient conditions (temperature, $2{ }^{\circ} \mathrm{C}$; relative humidity, $40 \pm 5 \%$; rotation speed of $2,000 \mathrm{rpm}$; acceleration speed of $2,000 \mathrm{rpm} / \mathrm{s}$ ). Si wafers were cleaned prior to spin coating by heating to $80{ }^{\circ} \mathrm{C}$ in the hydrogen peroxide-ammoniumwater mixture for $15 \mathrm{~min}$, followed by dilution with Millipore water, $15 \mathrm{~min}$ ultrasonication in hydrochloric acid-water mixture method, and dilution with Millipore water.
To uncover the surface of the titania particles, argon plasma treatment was applied by TECHNICS PlasmaProcessor 200-6 at $300 \mathrm{~W}$ for $10 \mathrm{~min}$. Plasma-etched titania nanocomposite films were heated up to $450^{\circ} \mathrm{C}$ under nitrogen atmosphere with a heating rate of $6.25{ }^{\circ} \mathrm{C} / \mathrm{min}$ starting from room temperature and kept at $450{ }^{\circ} \mathrm{C}$ for $4 \mathrm{~h}$. After calcination, the samples were cooled to room temperature in a furnace.

Characterization methods

Scanning electron microscopy (SEM) images were obtained on field emission SEM (LEO 1530 "Gemini") at an accelerating voltage of $3 \mathrm{kV}$.

$\mu$ GISAXS experiments were performed at the beamline BW4, at DESY HASYLAB in Hamburg, where parabolic beryllium compound refractive lenses are used to obtain a moderately micro-focused X-ray beam [26]. A beam size of $32 \times 23 \mu \mathrm{m}^{2}$ (height $\times$ width), synchrotron radiation with a wavelength of $1.38 \AA$, and incident on the sample surface at $0.74^{\circ}$ were used for the measurements. The sample detector distance for $\mu$ GISAXS was adjusted to $2.2 \mathrm{~m}$. The setup included a movable specular beam stop and a diode beam stop for the detection of direct beam intensity. A 2d-Mar CCD detector $(2,048 \times 2,048$ pixels $)$ was used to record the scattered X-rays.

Scanning force microscopy (SFM) images were recorded using a Veeco Dimension 3100 System (Veeco, Santa Barbara, USA) in tapping mode equipped with Si cantilevers (Olympus OMCL-AC240TS, Japan) having spring constant ranging between 33.2 and $65.7 \mathrm{~N} / \mathrm{m}$ and resonance frequency $370.4-319.7 \mathrm{kHz}$. The images were analyzed using the software Gywiddionttp://gwyddion.net/ [27].

PL spectra were recorded on a Spex FLUOROLOG II (212) using a Xenon discharge lamp at $400 \mathrm{~W}$. The emission spectra were collected at an excitation wavelength of $350 \mathrm{~nm}$.

\section{Results and discussion}

The titania triblock copolymer nanocomposite films with varying sol-gel compositions were prepared by spin coating on previously cleaned $\mathrm{Si}$ wafers. The obtained morphologies of the nanocomposite films were characterized in real space with microscopy techniques. Figure 1 shows the SFM and SEM images of as-prepared films. The scale bar in each image corresponds to $1 \mu \mathrm{m}$. However, one has to keep in mind that due to the low electron density difference between $\mathrm{Ti}$ and $\mathrm{Si}$, the obtainable magnification in SEM images is low. The standard solution of $1 \% \mathrm{HCl}$, $1 \%$ TTIP, and $1 \%$ polymer content sample is presented in Fig. 1c. In previous work, this concentration was chosen as 

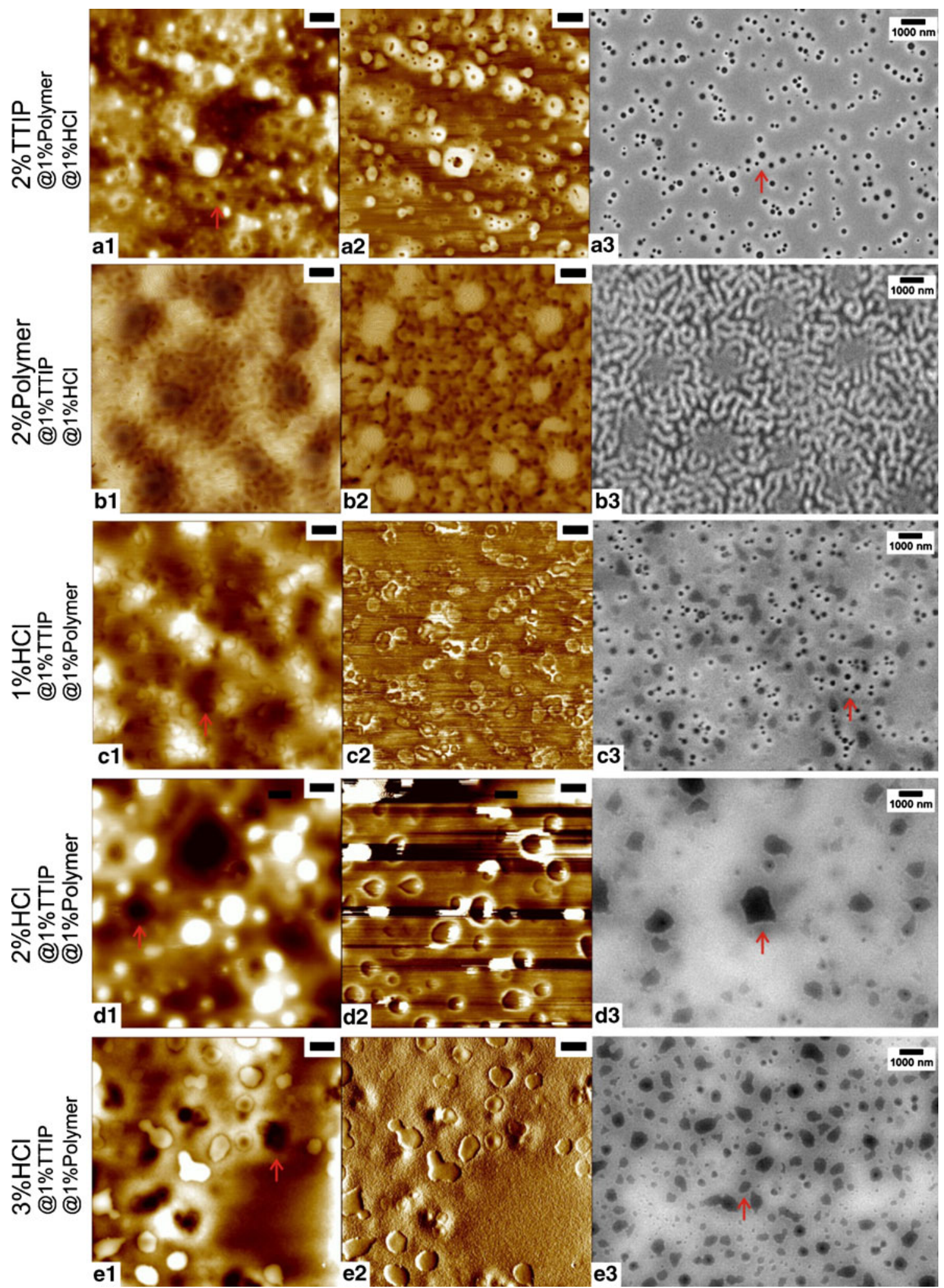

Fig. 1 SFM height (1), phase (2), and SEM (3) images of as-prepared samples: $2 \%$ TTIP $(a), 2 \%$ polymer $(b), 1 \% \mathrm{HCl}(c), 2 \% \mathrm{HCl}(d)$, and $3 \% \mathrm{HCl}(e)$. Height scales are $60 \mathrm{~nm}(a 1), 50 \mathrm{~nm}(b 1), 30 \mathrm{~nm}(c l)$,
$50 \mathrm{~nm}(d 1), 40 \mathrm{~nm}(e 1)$ with phase scales $40^{\circ}(a 2), 20^{\circ}(b 2), 3^{\circ}(c 2)$, $8^{\circ}(d 2)$, and $7^{\circ}(e 2)$. Scale bars correspond to $1 \mu \mathrm{m}$ 
the standard one according to the phase diagram for titania nanoparticle preparation using PS- $b$-PEO as the templating agent [15]. In our system, based on the triblock copolymer [(PEO)MA-PDMS-MA(PEO)], the templating agent and the corresponding solvents are different. Therefore, a different morphology is to be expected and was obtained [17].

The triblock copolymer, (PEO)MA-PDMS-MA(PEO), is a gel at room temperature. Therefore, tapping mode SFM images of as-prepared samples could be obtained on only $10-\mu \mathrm{m}^{2}$ sized areas. Some circular pits (made with red arrows on SFM and SEM images in Fig. 1) are seen on the surface as the observable morphology. These pits are due to the liquid-liquid miscibility gap which occurred during spin coating in the nanocomposite preparation step [28]. Increased titania precursor and $\mathrm{HCl}$ contents resulted in a similar morphology as compared to the standard solution (see Fig. 1a, d, e). A change in the overall film morphology was observed with an increased polymer content (see Fig. 1b). For the system containing PS- $b$-PEO, the variation of the block copolymer amount from $0.25 \%$ to $4 \%$ by weight resulted in a morphological change from mesoporous structures to lamellae [29]. A similar tendency was observed for varying the polymer content to $2 \%$ by weight.
The preparation of titania nanoparticles using a PDMS containing amphiphilic block copolymer results in an insulating polymer-derived ceramic in between titania nanoparticles after heat treatment under inert atmosphere. Inert atmosphere is required to prevent decomposition of the PDMS before it turns into ceramic. With this preparation route, nanocomposite films composed of conducting anatase titania nanoparticles embedded in an insulating matrix were obtained. However, to avoid insulation on the titania surface, plasma treatment is required before heating [17].

Next, the preparation of the titania films was continued with argon plasma etching to uncover the titania surface from any polymer and to achieve a conduction from the titania surface to the substrate. Afterwards, the films were heated to $450{ }^{\circ} \mathrm{C}$ under nitrogen atmosphere. This recipe results in a conductive titania network embedded in a polymer-derived insulating matrix. The resulting titania nanoparticles are in the anatase phase [17]. A removal of the (PEO)MA part of the block copolymer and the ceramization of PDMS resulted in a nanoporous inorganic film on the substrate, thereby enabling higher magnification imaging with SEM (Fig. 2, scale bars correspond to $200 \mathrm{~nm}$ ). The circular pits that occurred during spin coating
Fig. 2 SEM images of plasmatreated and annealed at $450{ }^{\circ} \mathrm{C}$ samples, $1 \% \mathrm{HCl}$ (a), $2 \% \mathrm{HCl}$ (b), $1 \% \mathrm{HCl}$ (c), $2 \%$ TTIP (d), and $2 \%$ polymer (e). Scale bars correspond to $200 \mathrm{~nm}$

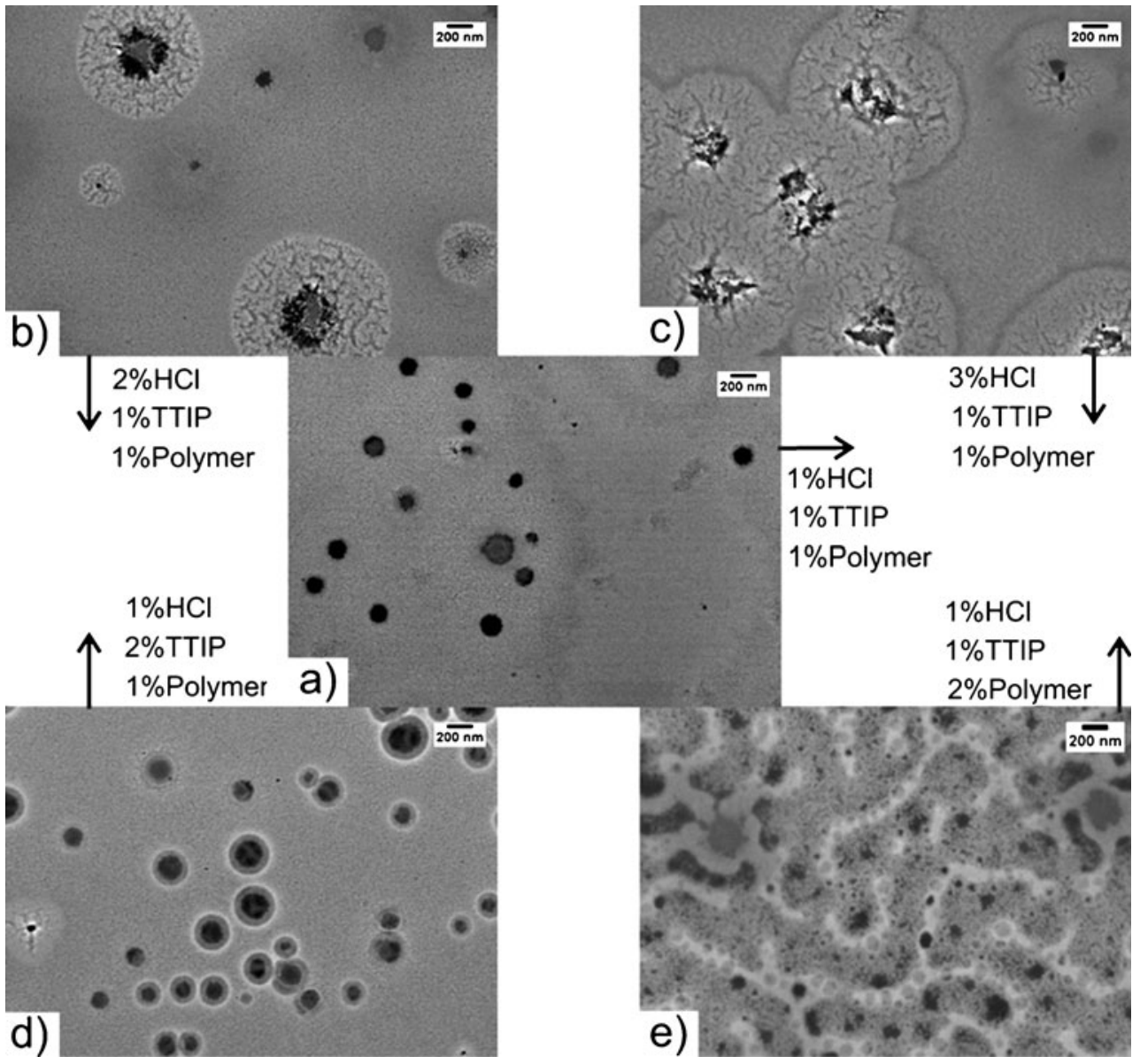


are observed again in these images. Although the circular pits of some hundred nanometers could be seen via SEM imaging, it remained difficult to image primary titania particles. $\mu$ GISAXS enabled to obtain information on the titania structures.

The structural stability of the particles was investigated by increasing the heating temperature further to $1,000{ }^{\circ} \mathrm{C}$. The particle diameters, averaged from the SEM images, are in the range of $14-40 \mathrm{~nm}$ for the $1 \% \mathrm{HCl}$ sample (in Fig. 3a), $12-48 \mathrm{~nm}$ for $2 \% \mathrm{HCl}$ sample (in Fig. 3b), $11-$ $42 \mathrm{~nm}$ for $3 \% \mathrm{HCl}$ sample (in Fig. 3c), 12-48 nm for $2 \%$ TTIP sample (in Fig. 3d), and 10-20 nm for 2\% polymer (in Fig. 3e, scale bars correspond to $200 \mathrm{~nm}$ ). These high magnification images give information on the smallest structures; however, the overall homogeneity of the film still remains unclear. For as-prepared films, microscopy did not provide much information since the softness of the polymer at room temperature and the low electron density difference between $\mathrm{Ti}$ and $\mathrm{Si}$ prevent high-resolution imaging. Moreover, microscopy techniques are restricted to an investigation in the micrometer square range and to the sample surface. For investigating the lateral structure of titania particles inside the films (thickness of $30 \pm 10 \mathrm{~nm}$ ) and the uniformity of the titania morphology in the nanocomposite film, we performed $\mu$ GISAXS measurements at the beamline BW4 in HASYLAB at DESY, Hamburg $[26,30]$. In general, $\mu$ GISAXS scattering patterns yield structural information averaged over the illuminated sample spots. In our case, this sample spot was of a size of $56,992 \mu \mathrm{m}^{2}(1,781 \times 32 \mu \mathrm{m})$. This is a consequence of the enlarged footprint at the chosen incident angle of $0.74^{\circ}$. The out-of-plane cuts at an exit angle equal to the critical angle of titania, $\alpha_{\mathrm{c}}=0.28^{\circ}$, were selected to obtain an averaged structure information about the percolating titania structures in a range from several nanometers up to $\sim 190 \mathrm{~nm}$. For a closer data analysis, the out-of-plane cuts were fitted according to the unified fit model [31-33]. This model was successfully applied to various scattering experiments in transmission geometry for different applications [31, 32, 3438]. We used the unified fit model to investigate the morphology of our titania structures in our previous investigations already [17, 39, 40]. This model describes the structure of the material in terms of structural levels, ranging from single particles to clusters. Each structural level contains a Guinier regime which describes the size and a power law regime giving the integral properties of the

Fig. 3 SEM images of plasma treated and annealed at $1,000{ }^{\circ} \mathrm{C}$ samples for $1 \% \mathrm{HCl}$ (a), $2 \% \mathrm{HCl}$ (b), $3 \% \mathrm{HCl}(\mathbf{c}), 2 \%$ TTIP (d), and $2 \%$ polymer composition (e). Scale bars correspond to $200 \mathrm{~nm}$. Arrows point the representative primary titania structures (L1) in all images, and the cluster size (L2) is depicted with a line in (a)

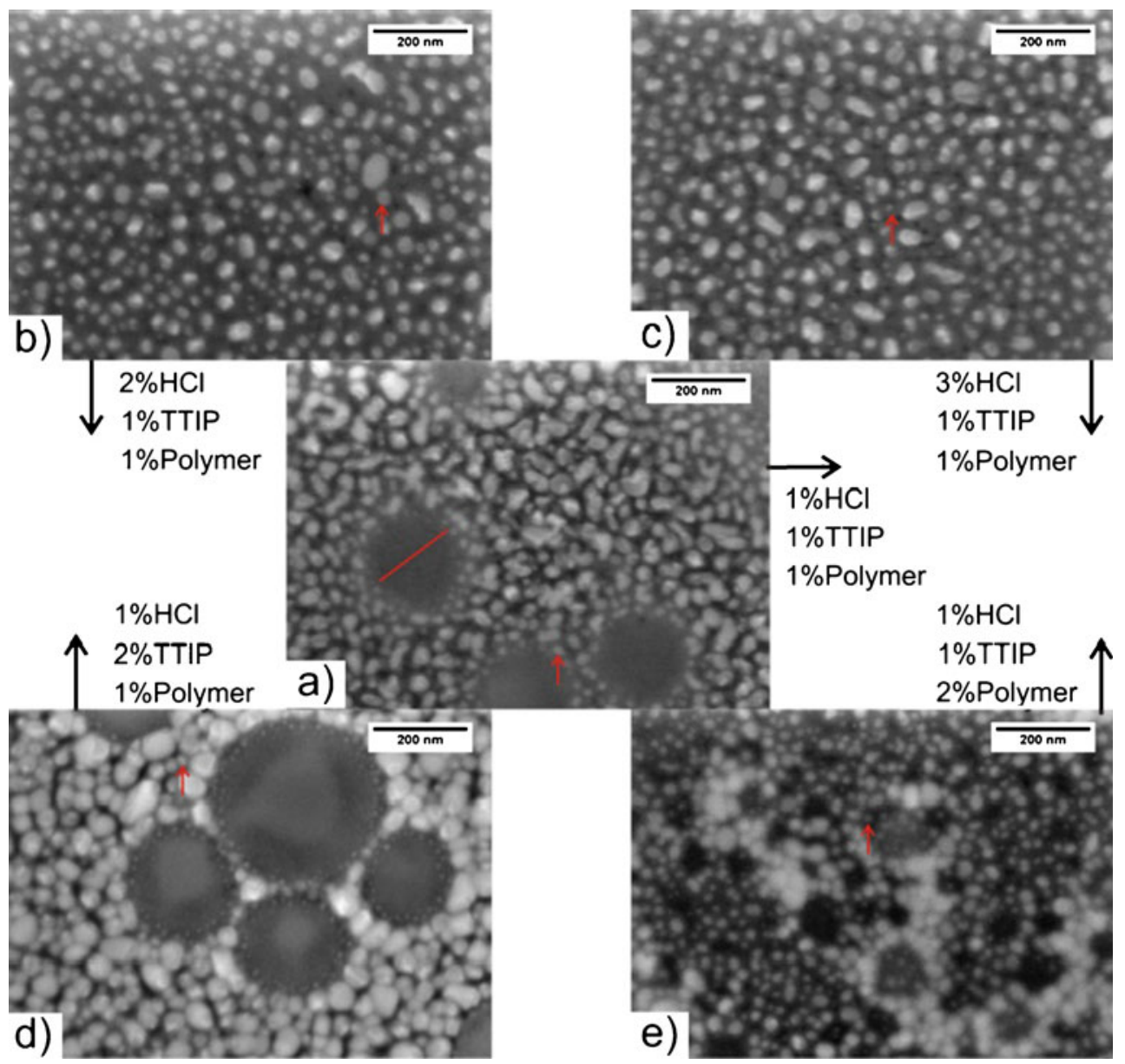


structure. The Porod regime provides information about the surface and mass fractality of the individual structure. Thus, it is possible to differentiate between smooth and jagged primary particle structures and between crystallike and disordered secondary cluster structures. Figure 4 shows the out-of-plane cuts together with fits which are

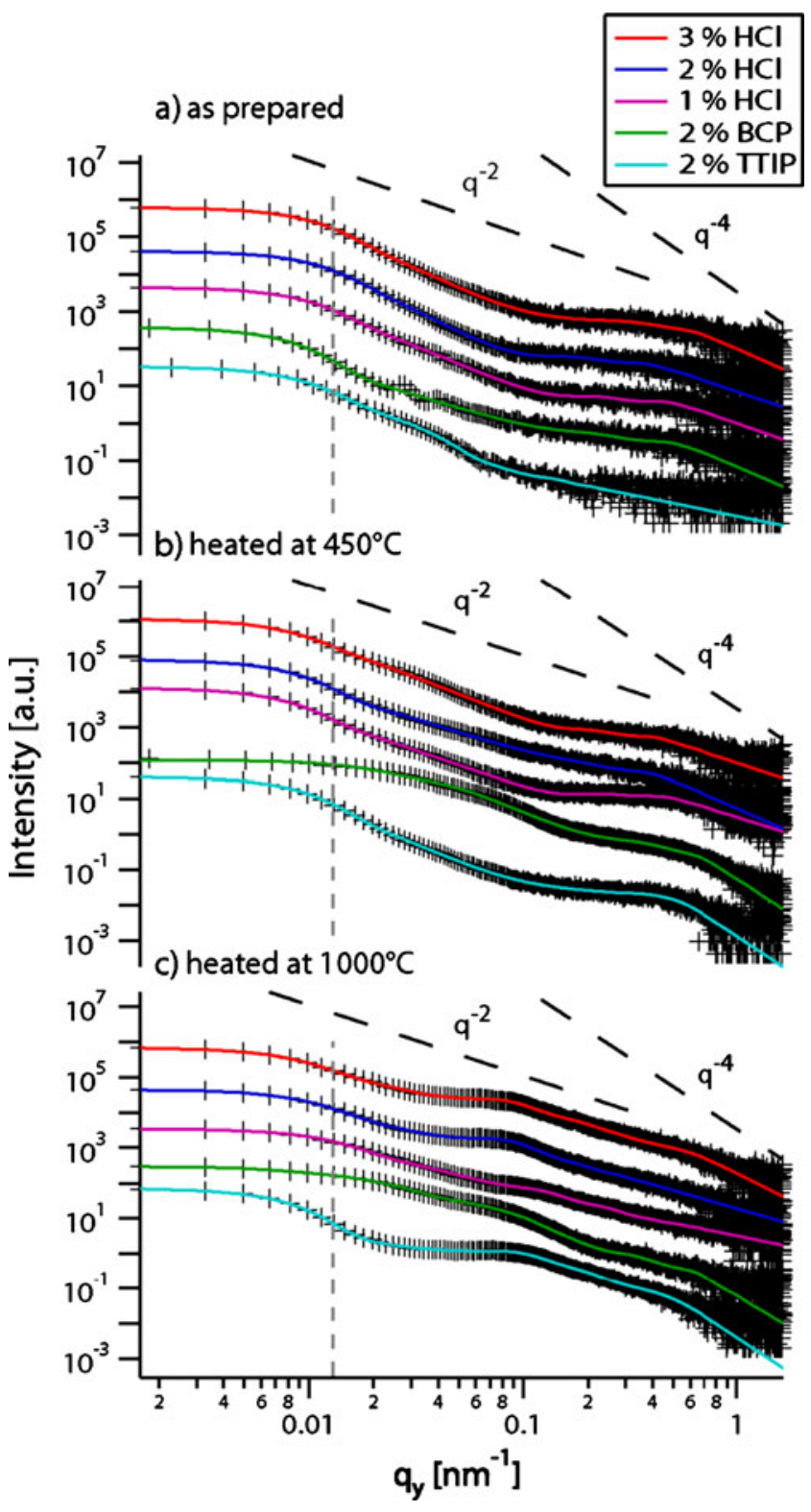

Fig. 4 Double-logarithmic plots of the out-of-plane cuts of the 2D intensity as a function of the $q_{y}$ component of the scattering vector. For clarity, the curves are shifted along the intensity axis. The dashed line indicates the resolution limit of the MGISAXS experiment. Colored lines are the fits, from unified fit model, for determining the prominent in-plane length scales, corresponding to the scattering data in black below them. From bottom to top, the curves correspond to samples from $2 \%$ TTIP (cyan), $2 \% \mathrm{BCP}$ (polymer, green), $1 \% \mathrm{HCl}$ (purple), $2 \% \mathrm{HCl}$ (blue), and $3 \% \mathrm{HCl}$ (red) concentration compositions in each graph. Upper graph (a) is for as-prepared, middle (b) is for heated at $450{ }^{\circ} \mathrm{C}$, bottom graph (c) is for heated at $1,000{ }^{\circ} \mathrm{C}$ samples overlaid on experimental data for as-prepared, heated at 450 and $1,000{ }^{\circ} \mathrm{C}$, samples.

The progression of the $\mu$ GISAXS curves for different $\mathrm{HCl}$ concentrations is similar for the as-prepared nanocomposite films (Fig. 4-a). Detailed structural information obtained from the fits is tabulated in Table 1. The smallest structures, represented as level 1 (L1 in Table 1), were obtained from the fits corresponding to the high- $q$ region $\left(q>0.005 \mathrm{~nm}^{-1}\right)$. These small structures are comparable within the experimental errors for all samples, except the one with $2 \% \mathrm{HCl}$ concentration which is $20 \%$ larger than the standard solution $(1 \% \mathrm{HCl})$. An increase in the amount of polymer $(2 \% \mathrm{BCP}$, green curve) or titania precursor ( $2 \%$ TTIP, cyan curve) in the sol-gel process results in a different slope as compared with the standard solution (1\% $\mathrm{HCl}$, purple curve) and increased $\mathrm{HCl}$ concentrations ( $2 \% \mathrm{HCl}$, blue curve, and $3 \% \mathrm{HCl}$, red curve). This is reflected in a $9 \%$ reduction of the primary titania particle sizes compared to the particle size from the standard solution $(1 \% \mathrm{HCl})$. The unified fit model gives information about the structure and packing of the structures from the Porod regime. For example, smooth spherical particles' scattering decays with $q^{-4}$ dependence result in a $P$ value of 4 in the unified fit model and cylindrically symmetrical structures' scattering decays with $q^{-3}$ dependence with a $P$ of 3 [41]. The $P$ value also corresponds to the packing density of the structures. The packing of the smallest structures are similar as the $P$ value is around 2 for all as-prepared samples. These smaller structures in asprepared samples are amorphous after the hydrolysis of TTIP in the sol-gel on PEO domains. Therefore, low packing with a non-well-defined structure is expected after spin coating. The preparation of the anatase titania nanoparticles by the sol-gel method requires an annealing step. Formation of well-defined ordered structures is expected after this calcination step. The fitted $P$ value is around 4 for $2 \%$ TTIP and $2 \%$ polymer samples after annealing at $450{ }^{\circ} \mathrm{C}$.

The high-resolution SEM images obtained from samples annealed at $1,000{ }^{\circ} \mathrm{C}$ (Fig. 3) can be used for an interpretation of our $\mu \mathrm{GISAXS}$ results. In general, the corresponding unified fit $R_{\mathrm{g}}$ values for primary titania structures (structural level $1, \mathrm{~L} 1)$ of diameters $\left(2 R_{\mathrm{g}}\right) \sim 16 \mathrm{~nm}$ for $3 \% \mathrm{HCl}, \sim 13 \mathrm{~nm}$ for $2 \% \mathrm{HCl}, \sim 16 \mathrm{~nm}$ for $1 \% \mathrm{HCl}, \sim 13 \mathrm{~nm}$ for $2 \%$ polymer, and $\sim 15 \mathrm{~nm}$ for $2 \%$ TTIP match the diameters $\left(2 R_{\mathrm{g}}\right)$ of the structures shown in Fig. 3. A red arrow points the representative titania structure in each image. The amorphous titania particles crystallize during the annealing step. Meanwhile, the triblock copolymer, the templating agent, which is present among the particles, decomposes. Primary particles (L1) stack over each other and build a titania network. In some parts, a few particles merge together, resulting in a larger titania cluster; in some parts, more 
Table 1 Values obtained from unified fitted $\mu$ GISAXS data of as-prepared, heated at $450{ }^{\circ} \mathrm{C}$ and $1,000{ }^{\circ} \mathrm{C}$ samples, $\mathrm{P}$ and $\mathrm{R}_{\mathrm{g}}$ stand for packing density and radius of gyration, respectively

\begin{tabular}{|c|c|c|c|c|c|c|c|}
\hline \multirow[t]{2}{*}{ Sample } & & \multicolumn{2}{|c|}{ As-prepared } & \multicolumn{2}{|c|}{ Heated at $450{ }^{\circ} \mathrm{C}$} & \multicolumn{2}{|c|}{ Heated at $1,000{ }^{\circ} \mathrm{C}$} \\
\hline & & $P$ & $R_{\mathrm{g}}(\mathrm{nm})$ & $P$ & $R_{\mathrm{g}}(\mathrm{nm})$ & $P$ & $R_{\mathrm{g}}(\mathrm{nm})$ \\
\hline \multirow[t]{2}{*}{$3 \% \mathrm{HCl}$} & L 1 & $2.3 \pm 0.3$ & $6.7 \pm 0.9$ & $2.4 \pm 0.2$ & $7.9 \pm 0.5$ & $3.8 \pm 2.5$ & $7.8 \pm 0.1$ \\
\hline & L 2 & $2.8 \pm 0.1$ & $160 \pm 1.2$ & $2.3 \pm 0.1$ & & $2.1 \pm 0.5$ & \\
\hline \multirow[t]{2}{*}{$2 \% \mathrm{HCl}$} & L 1 & $1.9 \pm 0.1$ & $9.5 \pm 0.8$ & $2.6 \pm 0.1$ & $9.4 \pm 0.7$ & $3.8 \pm 0.5$ & $6.2 \pm 0.1$ \\
\hline & L 2 & $3.0 \pm 0.1$ & $152 \pm 0.9$ & $1.9 \pm 0.1$ & & $2.1 \pm 0.3$ & $166 \pm 0.1$ \\
\hline \multirow[t]{2}{*}{$1 \% \mathrm{HCl}$} & L 1 & $1.9 \pm 0.3$ & $7.0 \pm 0.7$ & $2.1 \pm 0.1$ & $8.0 \pm 0.3$ & $1.7 \pm 0.1$ & $8.0 \pm 0.5$ \\
\hline & L 2 & $2.4 \pm 0.1$ & $170 \pm 1.7$ & $2.3 \pm 0.1$ & & $1.7 \pm 0.1$ & $131 \pm 1.1$ \\
\hline $2 \%$ & L 1 & $2.5 \pm 0.4$ & $6.4 \pm 0.6$ & $4.0 \pm 0.1$ & $6.0 \pm 0.2$ & $3.9 \pm 2.8$ & $6.5 \pm 1.6$ \\
\hline Polymer & L 2 & $1.8 \pm 0.1$ & & $2.5 \pm 0.1$ & $75 \pm 0.8$ & $1.5 \pm 0.4$ & $171 \pm 11$ \\
\hline \multirow[t]{2}{*}{ 2\%TTIP } & L 1 & $1.5 \pm 0.3$ & $6.4 \pm 0.7$ & $4.0 \pm 0.4$ & $7.3 \pm 0.5$ & $4.0 \pm 0.2$ & $7.7 \pm 0.4$ \\
\hline & L 2 & $2.4 \pm 0.5$ & & $2.6 \pm 0.1$ & & $1.9 \pm 0.4$ & \\
\hline
\end{tabular}

particles are joined together, resulting in a broad particle size distribution and increasing the polydispersity in particle size distribution. As observed from the SEM images, the particle sizes are not identical but not very different at the same time with a low aspect ratio. This is the major reason why sharp peaks could not be observed via X-ray scattering [42]. The cluster size (L2) obtained from the fit for $1 \% \mathrm{HCl}$ standard solution gives an $R_{\mathrm{g}}$ value of $130 \mathrm{~nm}$, resulting in a diameter $\left(2 R_{\mathrm{g}}\right)$ of $\sim 260 \mathrm{~nm}$. Figure 3 a shows circular pits of size $200 \mathrm{~nm}$ (pointed with a red line over the pit diameter), which is in agreement with the fit value. Structures with $R_{\mathrm{g}} \geq 190 \mathrm{~nm}$ $\left(2 R_{\mathrm{g}}>380 \mathrm{~nm}\right)$ are beyond the resolution limit of our $\mu$ GISAXS experiment. Therefore, the values for clusters could not be obtained and left as blank rows for some samples in Table 1. The arrows in Fig. 3 show the primary particles (L1) in each image; a cluster size (L2) is pointed in Fig. 3a. The information obtained from SEM images match the values obtained from the unified fit modeled $\mu$ GISAXS data. Here, $\mu$ GISAXS helps us to understand the overall morphology of continuous titania structures inside the whole film. After proving that $\mu$ GISAXS measurement data with the unified fit model reveal the structural information about the titania particles' morphology, we can discuss the structural changes of titania particles depending on the sol-gel composition according to the values obtained from the unified fit model of $\mu$ GISAXS experiments.

The structural stability of the titania structures upon elevated annealing temperature is observed by SEM imaging in correlation with GISAXS experiments. However, the crystallinity of the particles changed from amorphous to anatase and moreover to rutile, as observed from the X-ray diffraction (XRD) experiment (Fig. 5) after samples were prepared and heated to 450 and $1,000{ }^{\circ} \mathrm{C}$. Typical anatase titania peaks [6] are also depicted in Fig. 5 beneath the XRD curves. An as-prepared sample (Fig. 5a) is amorphous and showed no peak. After heating at $450{ }^{\circ} \mathrm{C}$, typical anatase titania peaks were observed (Fig. 5b). Further increase in heating temperature to $1,000{ }^{\circ} \mathrm{C}$ resulted in additional rutile phase, as indicated by additional XRD peaks (Fig. 5c). For application in semiconducting material requiring devices, anatase titania is needed. Heating temperature of $450{ }^{\circ} \mathrm{C}$ is less costly and destructive to the substrate than treatment at $1,000{ }^{\circ} \mathrm{C}$. Moreover, rutile phase which will act as an impurity among anatase particles was observed after heating to $1,000{ }^{\circ} \mathrm{C}$.

Figure 4-b shows the $\mu$ GISAXS experimental data (black data points) with overlaid fit results (colored lines) for plasma-treated and annealed at $450{ }^{\circ} \mathrm{C}$ samples. The progression of $2 \%$ BCP (polymer) sample changes significantly from the as-prepared curve compared to the change between other compositions' as-prepared ones. The slope of $2 \%$ BCP (polymer) changed and a broad peak in the

(c)

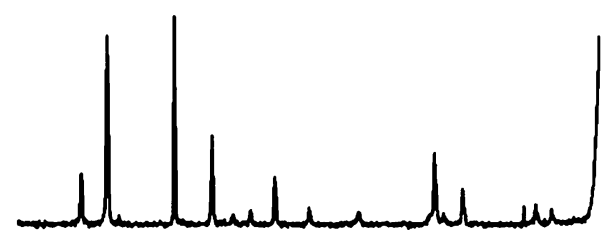

(b)

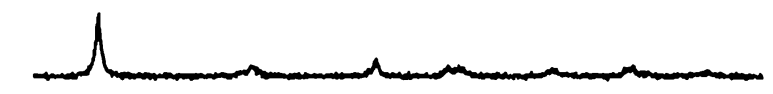

(a)

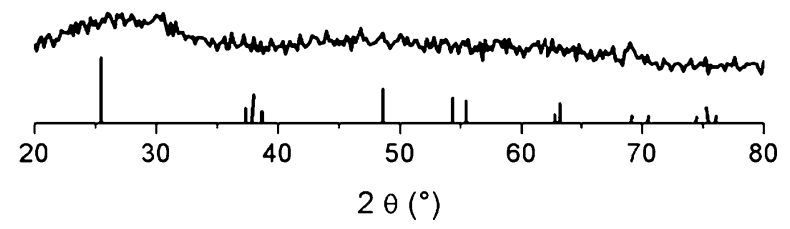

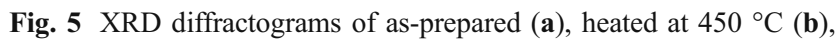
and heated at $1,000{ }^{\circ} \mathrm{C}$ (c) $1 \% \mathrm{HCl}$ samples (standard sol-gel). Typical anatase titania peaks [6] are shown at the bottom 
medium- $q$ range $\left(0.5 \mathrm{~nm}^{-1}\right)$ appeared, indicating a different secondary structure than present in the as-prepared sample. This results in smaller secondary structures (L2) with a diameter $\left(2 R_{\mathrm{g}}\right)$ of $150 \mathrm{~nm}\left(R_{\mathrm{g}} \sim 75 \mathrm{~nm}\right.$ obtained from the fit, L2). As also seen from the high-resolution SEM image in Fig. 3e, large circular pits are absent, and this is the case for the whole sample giving a narrow size difference between clusters, allowing better packing of the particles. The size of the primary titania structures (L1) did not change within the experimental errors compared to asprepared samples. This indicates that plasma cleaning and heating steps do not affect the smallest primary structures. The organic material in between the titania structures changes during the heat treatment. Since the material properties changed after the heating step, i.e., PDMS turned into silicon oxycarbide, organic polymer decomposed, amorphous titania turned into its anatase phase, and the scattering length density of the material changed. Removal of the organic part of the nanocomposite films increased the distance between the particles. The packing of the primary particles (L1) also increased and a $P$ value of 4 , corresponding to densely packed spherical particles, was observed for both $2 \%$ TTIP and $2 \%$ polymer contents. A $\mathrm{HCl}$ content variation resulted in $P$ values of $2-2.5$, indicating less closely packed and amorphous, in terms of shape, cylindrical primary structures. Larger cluster size for all $\mathrm{HCl}$ and 2\% TTIP samples were beyond the resolution limit of $\mu$ GISAXS measurements. Smaller titania primary structures were obtained with increase in TTIP and polymer contents.
This study revealed information on the relation between the sol-gel components and titania morphology when titania nanoparticles are prepared in an insulating matrix. Tiny changes in the conductive and insulating sources of the sol-gel affected the final morphology most. This is shown by the correlation between SEM images (Fig. 3) and the $\mu$ GISAXS experimental data fits in Table 1 . The electro-optic and photoelectric properties of these morphologies were investigated via PL spectroscopy which depends on electronic excitations [43]. PL is used to detect the surface defects occurring on titania nanoparticles, and a correlation between the titania morphology and electron active sites can be built. Figure 6 illustrates the PL spectra of samples after preparation and after heating at $450{ }^{\circ} \mathrm{C}$ under a 350-nm wavelength excitation source. Except $2 \%$ $\mathrm{HCl}$ content, all as-prepared samples exhibit higher PL intensity than the samples heated at $450{ }^{\circ} \mathrm{C}$. As shown by XRD measurements, titania is in amorphous state after preparation and turns into its anatase polymorph after calcination at $450{ }^{\circ} \mathrm{C}$. Higher surface defects and no crystallization in as-prepared samples result in higher PL intensity. As the amorphous titania nanoparticles turned into anatase phase, surface defects decreased and resulted in lower PL intensity. This also reveals that the photogenerated holes and electrons had the lowest recombination rate in samples heated at $450{ }^{\circ} \mathrm{C}$ [44]. Li et al.[44] also observed low emission intensity in PL measurements for anatase titania nanotubes which was due to good crystallization and fewer surface defects of the sample. PL curves for each sample were fitted with four Lorentzian peaks
Fig. 6 Photoluminescence spectra of as-prepared (solid points) and heated at $450{ }^{\circ} \mathrm{C}$ (open points) samples

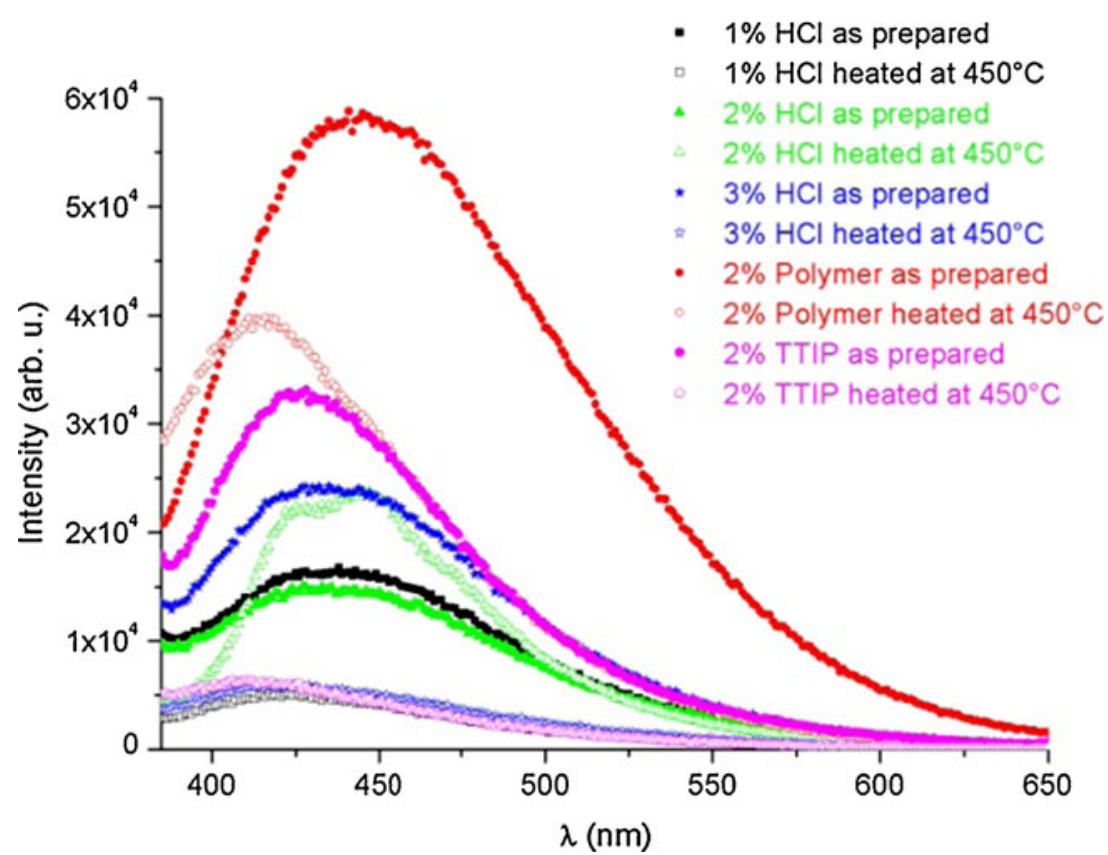


located at approx. 398, 435, 469, and $510 \mathrm{~nm}$, respectively. The peak at $398 \mathrm{~nm}$ can be assigned to self-trapped excitons localized in $\mathrm{TiO}_{6}$ octahedron, peaks at $469 \mathrm{~nm}$ to oxygen vacancies, and peaks at 435 and $510 \mathrm{~nm}$ to surface defects [43, 45-49].

The PL spectral peaks shifted to lower wavelengths after heating, and no peak at $510 \mathrm{~nm}$ could be observed. This indicates lower surface defects due to crystallization. The photoluminescence observed from $2 \%$ polymer after heating at $450{ }^{\circ} \mathrm{C}$ is mostly due to oxygen vacancies and self-trapped excitons. As the particle sizes become smaller, the oxygen vacancy content increases, resulting in higher probability of excitonic occurrence, thus higher excitonic PL signal [50]. The smallest primary titania structures (L1) were obtained by $2 \%$ polymer after heating to $450{ }^{\circ} \mathrm{C}$ (see Table $1, R_{\mathrm{g}} \sim 6 \mathrm{~nm}$ ). Other samples did not show considerable photoluminescence after heating, except $2 \%$ $\mathrm{HCl}$ which exhibited higher $\mathrm{PL}$ than as-prepared ones contrary to the amorphous-crystalline relation explained above. Two percent polymer content resulted in the smallest anatase titania nanoparticles with less surface defects, high oxygen vacancies.

Closely packed spherical-shaped titania particles with a diameter of 13-20 nm were obtained by varying the sol-gel composition to $2 \%$ polymer. This particle size is in the range of exciton diffusion length [25]. Their PL measurements showed less surface defects with high PL due to oxygen deficiencies and self-trapped excitons.

\section{Conclusions}

Titania nanoparticles with different sizes have been prepared by changing the sol-gel components: $\mathrm{HCl}$, titania precursor (TTIP), and polymer (PEO)MA-PDMS-MA (PEO). The primary titania structure size decreased and their packing density increased with increasing the polymer or titania precursor contents. Removal of the organic parts via plasma and subsequent heat treatments enabled to obtain higher magnification microscope images. Titania particles sustained their shape upon heating up to $1,000{ }^{\circ} \mathrm{C}$. SEM images of $1,000{ }^{\circ} \mathrm{C}$ annealed titania nanoparticles were in good agreement with the results obtained from the unified fit of $\mu$ GISAXS experiments, which further revealed information on the lateral structures of the particles irrespective of annealing. A $2 \%$ polymer sol-gel concentration resulted in primary titania structure size on the order of 13-20 nm with extra photoactive properties. The preparation of smaller sized primary titania structures will allow easier packing of several titania particles over each other to form a titania column inside the nanocomposite film, building a pathway for electrons in DSSC applications.
Acknowledgement Financial supports from the Max Planck Society, German Science Foundation (SPP 1181, GU771/2 and MU1487/5), and provision of beam time and local support by HASYLAB at DESY are gratefully acknowledged.

Open Access This article is distributed under the terms of the Creative Commons Attribution Noncommercial License which permits any noncommercial use, distribution, and reproduction in any medium, provided the original author(s) and source are credited.

\section{References}

1. Suisalu A, Aarik J, Mandar H, Sildos I (1998) Spectroscopic study of nanocrystalline $\mathrm{TiO}_{2}$ thin films grown by atomic layer deposition. Thin Solid Films 336(1-2):295-298

2. Gratzel M (2001) Photoelectrochemical cells. Nature 414(6861):338344

3. Wang ZS, Kawauchi H, Kashima T, Arakawa H (2004) Significant influence of $\mathrm{TiO}_{2}$ photoelectrode morphology on the energy conversion efficiency of N719 dye-sensitized solar cell. Coordin Chem Rev 248(13-14):1381-1389

4. Roberson LB, Poggi MA, Kowalik J, Smestad GP, Bottomley LA, Tolbert LM (2004) Correlation of morphology and device performance in inorganic-organic $\mathrm{TiO}_{2}$-polythiophene hybrid solid-state solar cells. Coordin Chem Rev 248(13-14):1491-1499

5. Yan MC, Chen F, Zhang JL, Anpo M (2005) Preparation of controllable crystalline titania and study on the photocatalytic properties. J Phys Chem B 109(18):8673-8678

6. Cozzoli PD, Kornowski A, Weller H (2003) Low-temperature synthesis of soluble and processable organic-capped anatase $\mathrm{TiO}_{2}$ nanorods. J Am Chem Soc 125(47):14539-14548

7. Baxter JB, Aydil ES (2005) Nanowire-based dye-sensitized solar cells. Appl Phys Lett 86(5):053114-053114-3

8. Law M, Greene LE, Johnson JC, Saykally R, Yang PD (2005) Nanowire dye-sensitized solar cells. Nat Mater 4(6):455-459

9. Coakley KM, McGehee MD (2003) Photovoltaic cells made from conjugated polymers infiltrated into mesoporous titania. Appl Phys Lett 83(16):3380-3382

10. Hosono E, Fujihara S, Kakiuchi K, Imai H (2004) Growth of submicrometer-scale rectangular parallelepiped rutile $\mathrm{TiO}_{2}$ films in aqueous $\mathrm{TiCl}_{3}$ solutions under hydrothermal conditions. J Am Chem Soc 126(25):7790-7791

11. Yin HB, Wada Y, Kitamura T, Kambe S, Murasawa S, Mori H, Sakata T, Yanagida S (2001) Hydrothermal synthesis of nanosized anatase and rutile $\mathrm{TiO}_{2}$ using amorphous phase $\mathrm{TiO}_{2}$. J Mater Chem 11(6):1694-1703

12. Luo HM, Wang C, Yan YS (2003) Synthesis of mesostructured titania with controlled crystalline framework. Chem Mater 15 (20):3841-3846

13. Sun ZC, Gutmann JS (2004) Synthesis of $\mathrm{TiO}_{2}$ nanoparticles in ultrathin block copolymer films - an integral geometry study. Physica A 339(1-2):80-85

14. Kim DH, Sun ZC, Russell TP, Knoll W, Gutmann JS (2005) Organic-inorganic nanohybridization by block copolymer thin films. Adv Funct Mater 15(7):1160-1164

15. Cheng YJ, Gutmann JS (2006) Morphology phase diagram of ultrathin anatase $\mathrm{TiO}_{2}$ films templated by a single PS- $b$-PEO block copolymer. J Am Chem Soc 128(14):4658-4674

16. Cheng YJ, Zhi L, Steffen W, Gutmann JS (2008) Surfacesupported, highly ordered macroporous crystalline $\mathrm{TiO}_{2}$ thin films robust up to $1,000^{\circ} \mathrm{C}$. Chem Mater 20(21):6580-6582

17. Memesa M, Weber S, Lenz S, Perlich J, Berger R, MüllerBuschbaum P, Gutmann JS (2009) Integrated blocking layers for hybrid organic solar cells. Energy Environ Sci 2(7):783-790 
18. Memesa M, Cheng YJ, Perlich J, Müller-Buschbaum P, Gutmann JS (2007) Integrated spin-on barrier layers a reasonable idea? Synth React Inorg, Met-Org, Nano-Met Chem 37(5):315-320

19. Weber S, Memesa M, Berger R, Butt H-J, Gutmann JS (2010) Electrical scanning probe microscopy of an integrated blocking layer. J Nanosci Nanotechnol 10:6840-6844

20. Pantano CG, Singh AK, Zhang HX (1999) Silicon oxycarbide glasses. J Sol-Gel Sci Techn 14(1):7-25

21. Zhang LF, Eisenberg A (1998) Formation of crew-cut aggregates of various morphologies from amphiphilic block copolymers in solution. Polym Advan Technol 9(10-11):677-699

22. Soo PL, Eisenberg A (2004) Preparation of block copolymer vesicles in solution. J Polym Sci Pol Phys 42(6):923-938

23. Discher DE, Eisenberg A (2002) Polymer vesicles. Science 297 (5583):967-973

24. Liu FT, Eisenberg A (2003) Preparation and $\mathrm{pH}$ triggered inversion of vesicles from poly(acrylic acid)-block-polystyreneblock-poly(4-vinyl pyridine). J Am Chem Soc 125(49):1505915064

25. Gunes S, Neugebauer H, Sariciftci NS (2007) Conjugated polymer-based organic solar cells. Chem Rev 107(4):1324-1338

26. Roth SV, Dohrmann R, Dommach M, Kuhlmann M, Kroger I, Gehrke R, Walter H, Schroer C, Lengeler B, Müller-Buschbaum P (2006) Small-angle options of the upgraded ultrasmall-angle Xray scattering beamline BW4 at HASYLAB. Rev Sci Instrum 77 (8):085106-085106-7

27. http://gwyddion.net/

28. Gutmann JS, Müller-Buschbaum P, Stamm M (1999) Complex pattern formation by phase separation of polymer blends in thin films. Faraday Discuss 112:285-297

29. Cheng YJ, Zhou SY, Gutmann JS (2007) Morphology transition in ultrathin titania films: from pores to lamellae. Macromol Rapid Comm 28(13):1392-1396

30. Müller-Buschbaum P (2003) Grazing incidence small-angle X-ray scattering: an advanced scattering technique for the investigation of nanostructured polymer films. Anal Bioanal Chem 376(1):3-10

31. Beaucage G, Rane S, Sukumaran S, Satkowski MM, Schechtman LA, Doi Y (1997) Persistence length of isotactic poly(hydroxy butyrate). Macromolecules 30(14):4158-4162

32. Beaucage G (1996) Small-angle scattering from polymeric mass fractals of arbitrary mass-fractal dimension. J Appl Crystallogr 29:134-146

33. Beaucage G (1995) Approximations leading to a unified exponential power-law approach to small-angle scattering. J Appl Crystallogr 28:717-728

34. Rathgeber S, Pakula T, Urban V (2004) Structure of star-burst dendrimers: a comparison between small angle X-ray scattering and computer simulation results. J Chem Phys 121(8):3840-3853

35. Norman AI, Ho DL, Karim A, Amis EJ (2005) Phase behavior of block co-poly(ethylene oxide-butylene oxide), E18B9 in water, by small angle neutron scattering. J Colloid Interf Sci 288(1):155-165

36. Chavan SV, Sastry PU, Tyagi AK (2006) Deagglomeration and fractal behavior of $\mathrm{Y}_{2} \mathrm{O}_{3}$ nano-phase powders. Scripta Mater 55 (6):569-572

37. Tappan BC, Huynh MH, Hiskey MA, Chavez DE, Luther EP, Mang JT, Son SF (2006) Ultralow-density nanostructured metal foams: combustion synthesis, morphology, and composition. J Am Chem Soc 128(20):6589-6594

38. di Stasio S, Mitchell JBA, LeGarrec JL, Biennier L, Wulff M (2006) Synchrotron SAXS (in situ) identification of three different size modes for soot nanoparticles in a diffusion flame. Carbon 44 (7):1267-1279

39. Lenz S, Bonini M, Nett SK, Lechmann MC, Emmerling SGJ, Kappes RS, Memesa M, Timmann A, Roth SV, Gutmann JS (2010) Global scattering functions: a tool for grazing incidence small angle X-ray scattering (GISAXS) data analysis of low correlated lateral structures. Eur Phys J Appl Phys 51(1):10601

40. Lenz S, Nett SK, Memesa M, Roskamp RF, Timmann A, Roth SV, Berger R, Gutmann JS (2010) Thermal response of surface grafted two-dimensional polystyrene (PS)/polyvinylmethylether (PVME) blend films. Macromolecules 43(2):1108-1116

41. Higgins JS, Benoit H (1994) Polymers and neutron scattering. Oxford University Press, Oxford

42. Perlich J, Schulz L, Abul Kashem MM, Cheng Y-J, Memesa M, Gutmann JS, Roth SV, Müller-Buschbaum P (2007) Modification of the morphology of $\mathrm{P}\left(\mathrm{S}-b\right.$-EO) templated thin $\mathrm{TiO}_{2}$ films by swelling with PS homopolymer. Langmuir 23:10299-10306

43. Sun ZC, Kim DH, Wolkenhauer M, Bumbu GG, Knoll W, Gutmann JS (2006) Synthesis and photoluminescence of titania nanoparticle arrays templated by block-copolymer thin films. Chemphyschem 7(2):370-378

44. Li G, Liu ZQ, Lu J, Wang L, Zhang Z (2009) Effect of calcination temperature on the morphology and surface properties of $\mathrm{TiO}_{2}$ nanotube arrays. Appl Surf Sci 255(16):7323-7328

45. Nakamura R, Okamura T, Ohashi N, Imanishi A, Nakato Y (2005) Molecular mechanisms of photoinduced oxygen evolution, PL emission, and surface roughening at atomically smooth (110) and (100) $n-\mathrm{TiO}_{2}$ (rutile) surfaces in aqueous acidic solutions. J Am Chem Soc 127(37):12975-12983

46. Tang H, Berger H, Schmid PE, Levy F, Burri G (1993) Photoluminescence in $\mathrm{TiO}_{2}$ anatase single crystals. Solid State Commun 87:847-850

47. Serpone N, Lawless D, Khairutdinov R (1995) J Phys Chem 99:16646

48. Forss L, Schubnell M (1993) Appl Phys B 56:363

49. Zhang WF, Zhang MS, Yin Z, Chen Q (2000) Appl Phys B 70:261

50. Jing LQ, Fu HG, Wang BQ, Xin BF, Li SD, Sun JZ (2006) Effects of Sn dopant on the photoinduced charge property and photocatalytic activity of $\mathrm{TiO}_{2}$ nanoparticles. Appl Catal, B 62(3-4):282-291 